\title{
Risico's verbonden aan Enterobacter sakazakii in zuigelingenvoeding
}

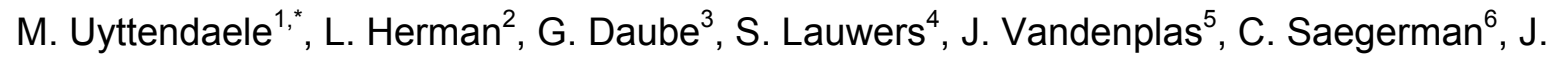
Debevere $^{1}$

${ }^{1}$ Laboratorium voor Levensmiddelenmicrobiologie en -conservering

Vakgroep Voedselveiligheid en Voedselkwaliteit, Faculteit Bio-ingenieurswetenschappen, Universiteit Gent, Gent

${ }^{2}$ Departement Kwaliteit Dierlijke Producten en Transformatietechnologie, Centrum voor Landbouwkundig Onderzoek, Melle

${ }^{3}$ Service de Microbiologie des Denrées Alimentaires d'origine Animale, Faculté de Médecine Vétérinaire de Liège, Liège.

${ }^{4}$ Dienst Microbiologie en Ziekenhuishygiëne, Departement Klinische Biologie, Academisch Ziekenhuis - Vrije Universiteit Brussel, Brussel.

${ }^{5}$ Dienst Pediatrie, Academisch Ziekenhuis - Vrije Universiteit Brussel, Brussel.

${ }^{6}$ Federaal Agentschap voor de Veiligheid van de Voedselketen (FAVV), Brussel

* Correspondentieadres: Prof. dr. ir. M. Uyttendaele, Laboratorium voor Levensmiddelenmicrobiologie en -conservering, FBW - UGent, Coupure Links 653, B-9000 Gent 


\section{Samenvatting (200 woorden)}

Enterobacter sakazakii is een zeldzame maar bekende oorzaak van neonatale sepsis en een ernstig verlopende vorm van meningitis met een mortaliteit van 10 tot $80 \%$. Verschillende infecties zijn in verband gebracht met de consumptie van zuigelingenvoeding. In opdracht van het FAVV (Federaal Agentschap voor de Veiligheid van de Voedselketen) werd een studie verricht met betrekking tot het contaminatieniveau, de voorwaarden voor groei en overleving en de risico's op infectie van E. sakazakii in zuigelingenvoeding. Dit met het oog op het formuleren van richtlijnen omtrent de voorwaarden voor bereiding, bewaring en toediening van zuigelingenvoeding .

Melkpoeder is niet absoluut steriel is en een mogelijks lage besmetting (productienorm: $<1$ kve per 10g) met E. sakazakii kan aanwezig zijn. Bij bereiding moeten de nodige hygiënische maatregelen in acht worden genomen. Er wordt aanbevolen de bereide zuigelingenvoeding binnen maximaal $2 \mathrm{~h}$ te koelen tot $5^{\circ} \mathrm{C}$ en een maximum bewaartijd van $24 \mathrm{~h}$ te respecteren. Opwarmen van het gerehydrateerd melkpoeder tot $37^{\circ} \mathrm{C}$, warm houden en toedienen van bereide zuigelingenvoeding is een totaalproces dat maximum $1 \mathrm{~h}$ in beslag mag nemen opdat er zich een voldoende marge tussen het aantal E. sakazakii cellen en de infectieve dosis zou bevinden. Door opvolgen van deze richtlijnen kan het risico op neonatale $E$. sakazakiiinfecties sterk gereduceerd worden.

\section{Trefwoorden}

Enterobacter sakazakii, zuigelingenvoeding, melkpoeder, neonatale sepsis, meningitis 


\section{Abstract (250 woorden)}

Enterobacter sakazakii has been implicated in a severe form of neonatal meningitis in infants with a mortality of 10 to $80 \%$. Several cases were associated with the consumption of powdered milk formula. Due to a demand of the Federal Food Agency in Belgium a study was undertaken to collect information with regard to the contamination level, growth and survival characteristics and infective dose of $E$. sakazakii in powdered milk formula. This study was the basis for the development of recommendations with regard to the conditions for preparation, storage and feeding procedure.

The production process of milk powder does not guarantee an absolute sterile product and low levels of $E$. sakazakii (<1 cfu per $10 \mathrm{~g}$ ) may occasionally be present. During preparation of powdered milk formula in the kitchen good hygienic practices are a prerequisite. It is recommended that the prepared powdered milk formula are cooled down to $5^{\circ} \mathrm{C}$ in less than 2 hours and that refrigerated storage is limited to a maximum of $24 \mathrm{~h}$. Warming up the rehydratated milk powder to $37^{\circ} \mathrm{C}$, keeping the infant formula at the body temperature and feeding is a process that overall should not take more than one hour in order to keep a safety margin between the numbers of $E$. sakazakii cells potentially present and the infective dose of the pathogen. If the above mentioned guidelines for preparation, storage and feeding of powdered milk formula are respected, the risk of a neonatal $E$. sakazakii-infection could be dramatically reduced. 


\section{Inleiding}

Enterobacter sakazakii is een zeldzame maar bekende oorzaak van neonatale sepsis en een ernstig verlopende vorm van meningitis (1) met een mortaliteit van 10 tot $80 \%(2,3)$. Verschillende infecties zijn in verband gebracht met de consumptie van zuigelingenvoeding. In de Verenigde Staten wordt het aantal invasieve infecties met Enterobacter sakazakii bij baby's (< 12 maanden) op basis van surveillance studies geschat op 1 per 100,000 kinderen (4). In december 2004 werd melding gemaakt van een infectie met Enterobacter sakazakii met dodelijke afloop bij twee zuigelingen in Frankrijk (5). In 2002 werd in Aalst de melding gemaakt van een pasgeborene die door de bacterie Enterobacter sakazakii aan neonatale meningitis is overleden (6). Tevens werden in de periode juni-juli 1998 een aantal gevallen van Enterobacter sakazakii infectie gerelateerd aan gecontamineerd melkpoeder genoteerd in het Academisch Ziekenhuis in Brussel. Twaalf neonaten (prematuren) werden toen besmet en twee kindjes zijn toen overleden (7).

Dit heeft reeds in 2002 geleid tot een advies van de Hoge Gezondheidsraad met betrekking tot neonatale infecties veroorzaakt door Enterobacter Sakazakii in zuigelingenvoeding in kraaminrichtingen (8).

Recent heeft het Wetenschappelijk Comité van het Federaal Agentschap voor de Veiligheid van de Voedselketen (FAVV) een advies geformuleerd aangaande de risico's verbonden aan Enterobacter sakazakii in zuigelingenvoeding (9) naar aanleiding van een vraagstelling (vijf vragen) daterend van mei 2004 van de Gedelegeerd Bestuurder van het FAVV aan het Wetenschappelijk Comité om concrete richtlijnen uit te werken omtrent de voorwaarden (tijd en temperatuurslimieten) voor bereiding, bewaring en toediening van zuigelingenvoeding. Het Wetenschappelijk Comité heeft in eerste instantie een studie van de wetenschappelijke literatuur uitgevoerd met het oog informatie te verwerven omtrent de prevalentie, de mogelijkheden tot groei en overleving en de risico's op infectie verbonden aan het voorkomen van E. sakazakii in zuigelingenvoeding. Vervolgens is er op basis van de 
verworven informatie een analyse uitgevoerd om op wetenschappelijk verantwoorde manier aan de vraagstelling te beantwoorden. Tevens werd door consultatie van een aantal pediaters het advies getoetst op de haalbaarheid en duidelijkheid van de richtlijnen binnen het kader van een kraaminrichting.

\section{Incidentie en contaminatieniveau van Enterobacter sakazakii in melkpoeder}

Momenteel zijn in de EU geen criteria beschikbaar voor E. sakazakii in melkpoeder. Wel wordt gesteld dat in melkpoeder coliformen moeten afwezig zijn in $0.1 \mathrm{~g}(<10 / \mathrm{g})$ (EU wetgeving). The FAO "code of practice" eist $<3$ coliformen per $g$ in minimum $4 / 5$ monsters met maximum 1/5 $>3$ maar $\leq 20$ coliformen per $\mathrm{g}$. Verschillende firma's hanteren voor vrijgave van melkpoeder een criterium van afwezigheid van $E$. sakazakii per $10 \mathrm{~g}(10)$.

Het productieproces van melkpoeder bestaat uit een aantal verschillende stappen nl. ontvangst en selectie van rauwe melk, clarificatie, koeling, opslag rauwe melk, standaardisatie, hittebehandeling, evaporatie, homogenisatie, sproeidrogen en verpakken en opslag. Enterobacteriaceae zullen, bij een procesuitvoering onderworpen aan het verplicht autocontrolesysteem, het productieproces van melkpoeder niet overleven. Deze groep van micro-organismen is echter dikwijls aanwezig in de omgeving van het productieproces. $E$. sakazakii werd teruggevonden in de productieomgeving van vier fabrieken die melkpoeder produceerden, maar Enterobacter werd ook teruggevonden in de productieomgeving van fabrieken die ontbijtgranen, chocolade en pasta produceerden (11).

E. sakazakii blijkt resistenter te zijn dan andere Enterobacteriaceae tegenover drogen wat de persistentie van dit micro-organisme in deze fabrieksomgeving kan verklaren (12).

Deze micro-organismen kunnen uiteindelijk in het afgewerkte product (melkpoeder) terechtkomen als er post-procescontaminatie optreedt.

Enterobacteriaceae werden geïsoleerd uit $52 \%$ van 141 productmonsters zuigelingenvoeding afkomstig van 35 landen. De species die het meest geïsoleerd werden zijn Enterobacter agglomerans, Enterobacter cloacae, Enterobacter sakazakii en Klebsiella pneumoniae. In 
geen enkel product was de concentratie hoger dan $1 \mathrm{kve} / \mathrm{g}$ en in $78 \%$ van alle positieve productmonsters was de concentratie $1 \mathrm{kve} / 100 \mathrm{~g}$ of lager, en dus binnen de huidige wettelijke bepalingen. De hoogste concentratie die werd vastgesteld was $92 \mathrm{kve} / 100 \mathrm{~g}$ (Enterobacter cloacae) (13). Door Nazarowec-White en Farber (1997) (14) werden 8 van de 120 onderzochte monsters melkpoeder positief bevonden voor $E$. sakazakii waarbij het niveau max 1 kve per $100 \mathrm{~g}$ bedraagt. In melkpoeder geassocieerd met een E. sakazakii infectie werd een initieel contaminatieniveau van $4 \mathrm{kve} / 100 \mathrm{~g}(6)$ tot $8 \mathrm{kve} / 100 \mathrm{~g}$ vastgesteld (10).

\section{Temperatuurslimieten en hitteresistentie van Enterobacter sakazakii}

De minimale temperatuur voor groei van 10 geteste isolaten varieert tussen $5,5^{\circ} \mathrm{C}$ tot $8^{\circ} \mathrm{C}$. Gedurende bewaring bij $4^{\circ} \mathrm{C}$ zal het micro-organisme langzaam afsterven. De gemiddelde generatietijd in de studie van Nazarowec-White en Farber (1997) (14) was 40 minuten $(0,67 \mathrm{~h})$ bij $23^{\circ} \mathrm{C}$ en $4,98 \mathrm{~h}$ bij $10^{\circ} \mathrm{C}$. De lag-fase bij $10^{\circ} \mathrm{C}$ bedroeg gemiddeld $32,8 \mathrm{~h}$ (met een minimum van $18,96 \mathrm{~h}$ ) en bij $23^{\circ} \mathrm{C}$ gemiddeld $2,76 \mathrm{~h}$ (met een minimum van $1,76 \mathrm{~h}$ ). Deze waarden zijn laag in vergelijking met de waarden van andere Enterobacteriaceae. De lagfase werd bepaald met stammen gekweekt onder optimum laboratoriumcondities. Er werd hierbij geen rekening gehouden met een eventuele verlenging van de lag-fase ten gevolge van voorafgaandelijke blootstelling aan stressomstandigheden (vb. dehydratatie in melkpoeder).

Iversen en Forsythe (2003)(10) en Iversen et al. (2004) (15) rapporteerden generatietijden van $13,6 \mathrm{~h} ; 2,9 \mathrm{~h} ; 1,3 \mathrm{~h}$ en $0,5 \mathrm{~h}$ bij respectievelijk $10^{\circ} \mathrm{C} ; 18^{\circ} \mathrm{C} ; 21^{\circ} \mathrm{C}$ en $37^{\circ} \mathrm{C}$.

Hoewel er telkens slechts lage hoeveelheden E. sakazakii worden teruggevonden in melkpoeder kan dit organisme door zijn relatief korte lag-fase en generatietijd redelijk vlug uitgroeien in gerehydrateerd melkpoeder wanneer dit niet bij de juiste temperatuur wordt bewaard. 
Wat betreft hitteresistentie zijn er uiteenlopende rapporteringen.

Door Nazarowec-White en Farber (1997) (16) werden D-waarden vermeld van 4,20 minuten bij $58^{\circ} \mathrm{C}$ en $2,50 \mathrm{~min}$ bij $60^{\circ} \mathrm{C}$.

Recent toonden Breeuwer et al. (2003) (12) aan dat E. sakazakii niet uitzonderlijk thermotolerant was maar wel geadapteerd is aan osmotische stress en droogte. De Dwaarde bij $58^{\circ} \mathrm{C}$ bedroeg $0,39-0,60$ minuten.

Door Edelson-Mammel en Buchanan (2004) (17) werden D-waarden vastgesteld bij $58^{\circ} \mathrm{C}$ in gerehydrateerd melkpoeder voor diverse stammen van $E$. sakazakii die uiteenlopen van 30,5 $\sec$ tot $591,9 \sec (9,86 \mathrm{~min})$ waarbij twee fenotypes met betrekking tot hitteresistentie werden vastgesteld. Voor de meest hitteresistente stam werd een z-waarde van $5,6^{\circ} \mathrm{C}$ vastgesteld. Wanneer rehydratatie van melkpoeder werd uitgevoerd met water van minimum $70^{\circ} \mathrm{C}$ werd voor deze stam ook een 4-log reductie vastgesteld. Rehydrateren met water bij verhoogde temperatuur kan aldus een beheersmaatregel zijn maar het is niet duidelijk of dit eventueel de nutritionele waarde niet beïnvloedt. Tevens moet in dit geval ook gezorgd worden dat de bereide zuigelingenvoeding voldoende wordt afgekoeld voor toediening om te voorkomen dat de zuigeling zich verbrandt.

Op basis van de bepaling van de thermotolerantie van $E$. sakazakii kon afgeleid worden dat de decimale reductietijd van de pathogeen bij $71,2^{\circ} \mathrm{C} \quad 0,7$ seconden bedraagt en aldus de standaard hoge temperatuur, korte tijd pasteurisatie (HTST) van 15 seconden bij $71,7^{\circ} \mathrm{C}$ zal resulteren in ca. 21 log reductie (15).

\section{Infectieve dosis van Enterobacter sakazakii}

De manifestatie van de ziekte in neonatale infecties is ernstig. Vooral premature pasgeborenen zijn vatbaar en kunnen sterven als gevolg van de infectie. Een sterftecijfer tot 40 en zelfs $80 \%$ wordt vermeld. Er is geen enkele literatuurbron die de mechanismen van pathogeniciteit of de mogelijke virulentiefactoren van E. sakazakii beschrijft. E. sakazakii zou bepaalde enterotoxines produceren. De pathogeniciteit bij muizen werd eveneens 
aangetoond bij proeven waarbij E. sakazakii aan muizen oraal $\left(10^{7}\right.$ cellen bij 2 van de 18 stammen, $>10^{8}$ bij de overige stammen nodig voor infectie) of intraperitonaal $\left(10^{5}\right.$ cellen bij 2 van de 18 stammen nodig voor infectie) werden toegediend (18). Het is echter niet duidelijk hoe deze proeven bij muizen moeten geïnterpreteerd worden in termen van infectieve dosis bij zuigelingen. Het is wel duidelijk dat verschillende stammen van E. sakazakii zullen verschillen in pathogeniciteit en infectieus vermogen.

$\mathrm{Er}$ is in de literatuur geen rapportering omtrent de infectieve dosis van E. sakazakii.

Bij het opstellen van een risicoprofiel voor E. sakazakii door Iversen en Forsythe (2003) (10) werd een infectieve dosis verondersteld van 1000 cellen (naar analogie met E. coli 0157 en Listeria monocytogenes) maar met betrekking tot deze veronderstelling werd de volgende commentaar en aanvulling geleverd door Havelaar en Zwietering (2004) (19).

- Op basis van een studie van Nazarowec-White en Farber (1997) (14) waarbij de concentratie gemiddeld 0.36 cellen per $100 \mathrm{~g}$ bedraagt (of 0.065 cellen per fles bereid met $18 \mathrm{~g}$ melkpoeder) werd berekend dat in dit geval $6.5 \%$ van de flesjes gecontamineerd zal zijn met maximum 1 cel (kleine kans van $0.2 \%$ dat één flesje 2 cellen bevat werd verwaarloosd).

- Wat betreft de infectieve dosis die op 1000 cellen werd verondersteld werd de opmerking gemaakt dat een infectieve dosis nooit een absolute grens is maar er eerder sprake is van een dosis-respons curve waarbij werd verondersteld dat ook één cel theoretisch een heel kleine kans op infectie zou hebben. Deze kans werd berekend op basis van een model dat werd opgesteld waarbij de auteurs veronderstellen dat 1000 cellen de dosis is die bij $50 \%$ van de blootgestelde personen infectie veroorzaakt en hieruit bleek dat de kans op infectie voor 1 cel dan $7 \times 10^{-4}$ zou bedragen.

- Zelfs indien geen groei zou optreden tijdens bereiding en bewaring en dus enkel 1 cel aanwezig zou zijn dan zou de kans op infectie bij consumptie van een ad random genomen flesje volgens de auteurs gelijk zijn aan $0.065 \times 7 \times 10^{-4}=5 \times 10^{-5}(=$ basisrisico 
zonder uitgroei van de pathogeen). Dit risico is redelijk hoog terwijl in praktijk het aantal gerapporteerde gevallen van E. sakazakii zeer laag is. Dit laat uitschijnen, zo vermelden Havelaar en Zwietering, dat de door hen gemaakte veronderstelling omtrent het dosisrespons curve model van $E$. sakazakii niet klopt met de realiteit en dit waarschijnlijk aanduidt dat het infectief karakter van E. sakazakii (voor één enkele cel) helemaal niet zo hoog is. Zij verwijzen daarbij ook naar de waarneming van Pagotto et al. (2003) (18) waarbij lethale infecties waarbij E. sakazakii aan muizen oraal werd toegediend slechts optreden bij ingestie van $10^{7}$ cellen bij 2 van de 18 stammen en $>10^{8}$ nodig is voor infectie bij de overige stammen.

Op basis van de bovenvermelde literatuurgegevens en naar analogie met de conclusie van Iversen et al. (2004) (15) wordt er verondersteld dat het weinig waarschijnlijk is dat de geringe hoeveelheden van E. sakazakii die in melkpoeders worden aangetoond een infectie kunnen veroorzaken. Langdurig bewaren van in water opgelost melkpoeder op kamer- en/of drinktemperatuur is evenwel de ideale groeibodem voor E. sakazakii. Het gebruik van fles(sen)verwarmers om de klaargemaakte voeding langdurig op temperatuur te houden moet bijgevolg vermeden worden. Een Duits artikel maakt in dit verband de aanbeveling om bereide zuigelingenvoeding niet langer dan 4 uren bij kamertemperatuur te bewaren (18). Bewaring in de koelkast en pas kort voor gebruik op temperatuur brengen is een betere methode.

Het gebruik van kant- en klare commercieel steriele vloeibare voeding vormt een alternatief maar het betreft hier de vraag of dit nutritioneel evenwaardig is (8) Bovendien zijn slechts een minderheid van de voedingen in vloeibare vorm beschikbaar. 


\section{Richtlijnen omtrent de voorwaarden voor bereiding, bewaring en toediening van zuigelingenvoeding}

Vraag 1: Binnen hoeveel tijd moet de bereide zuigelingenvoeding gekoeld worden en tot op $\underline{\text { welke temperatuur om het risico op besmetting zo klein mogelijk te houden? }}$

De tijd en temperatuur van bereiding van de zuigelingenvoeding heeft niet zozeer invloed op het risico op besmetting (wel de hygiënische maatregelen genomen) maar de tijd en temperatuur van bereiding hebben wel een invloed op het risico voor groei van $E$. sakazakii indien aanwezig in het melkpoeder aangewend voor bereiding. Daarentegen heeft de wijze van bereiding wel een invloed op het risico op besmetting. Bereiding moet gebeuren door goed opgeleid personeel dat kennis heeft van het feit dat melkpoeder niet absoluut steriel is en een mogelijks lage besmetting (<1 kve per $10 \mathrm{~g})$ met $E$. sakazakii kan aanwezig zijn. Bij bereiding moeten de nodige hygiënische maatregelen in acht worden genomen en de punten van aandacht of kritische punten in de melkkeuken moeten gekend zijn en beheerst worden in overeenstemming met de HACCP principes zoals tevens van toepassing voor "grootkeukens".

Wat betreft groei van E. sakazakii tijdens bereiding wordt verondersteld dat melkpoeder wordt gerehydrateerd bij kamertemperatuur met water bij kamertemperatuur (de exacte temperatuur van bereiding verschilt van poeder tot poeder afhankelijk van de oplosbaarheid). Er wordt verondersteld dat het melkpoeder voldoet aan de minimum norm (E. sakazakii afwezig per $10 \mathrm{~g}$ ) zodat er gezien de geringe hoeveelheid melkpoeder die gehanteerd wordt voor de bereiding van flessenvoeding voor zuigelingen $(15-40 \mathrm{~g})$ een begincontaminatie per flesje van ca. 1-2 cellen wordt verondersteld. Vervolgens wordt ook aangenomen dat na bereiding direct wordt gekoeld en niet wordt opgewarmd tot $37^{\circ} \mathrm{C}$ (opwarmen wordt behandeld in vraag 3$)$. Gezien de lag-fase bij kamertemperatuur $\left(23^{\circ} \mathrm{C}\right)$ gemiddeld $2,76 \mathrm{~h}$ bedraagt (minimum 1,76h), de generatietijd gemiddeld 40 minuten en de minimum groeitemperatuur $5,5^{\circ} \mathrm{C}-7^{\circ} \mathrm{C}$ wordt aanbevolen de bereide zuigelingenvoeding binnen 
maximaal $2 \mathrm{~h}$ te koelen tot $5^{\circ} \mathrm{C}$. De gehanteerde generatietijden en lag-fases zijn gebaseerd op literatuurgegevens die betrekking hebben op stammen die voorafgaandelijk onder optimale laboratoriumcondities werden opgekweekt en het is inderdaad zo dat gestresseerde bacteriën een aanzienlijke verlenging van hun lag-fase kunnen vertonen. De waarden uit de literatuur hanteren aldus een "worst case" scenario.

Vraag 2: Hoelang mag bereide zuigelingenvoeding bewaard worden in de koelkast en bij welke temperatuur?

Gezien groei bij $<5,5^{\circ} \mathrm{C}$ niet mogelijk is, is er geen probleem de bereide zuigelingenvoeding na bereiding en koeling binnen de $2 \mathrm{~h}$ tot $5^{\circ} \mathrm{C}$ te bewaren bij de maximale vermelde koeltemperatuur van $5^{\circ} \mathrm{C}$.

Eventueel transport van bereide zuigelingenvoeding dient gekoeld te gebeuren.

In het buitenland wordt een maximum bewaartijd van zuigelingenvoeding (bereid via gereconstitueerd melkpoeder) aangeraden van $24 \mathrm{~h}$. Dit wordt vermeld in een Nederlands (21) en een Canadees (22) rapport.

$\underline{\text { Vraag } 3: \text { Hoelang mag bereide zuigelingenvoeding op temperatuur (bain-marie) gehouden }}$ worden voor toediening aan de zuigeling?

Verondersteld wordt dat de temperatuur van de "bain-marie" (of equivalente verwarmingsmogelijkheid) voor opwarmen van de bereide zuigelingenvoeding voor toediening aan de zuigeling $37^{\circ} \mathrm{C}$ betreft. Gezien bij $37^{\circ} \mathrm{C}$ geen lag-fase wordt verondersteld en de gemiddelde generatietijd 30 minuten betreft (er wordt aangenomen dat omwille van variatie tussen stammen zoals vastgesteld bij $23^{\circ} \mathrm{C}$ de minimum generatietijd 20 minuten betreft) dan betekent dit dat 30 minuten bij $37^{\circ} \mathrm{C}$ maximaal aanleiding geeft tot 1 à 2 vermenigvuldigingen. De beginconcentratie in een fles bereide zuigelingenvoeding wordt maximaal ca. 1-2 cellen geacht (zie vraag 1) want tijdens bereiding en opslag in de koeling 
wordt geen groei verondersteld indien uitgevoerd onder de condities vermeld in vraag 1. Dus de aantallen E. sakazakii na 30 minuten zouden 4 tot 8 cellen per flesje zuigelingenvoeding bedragen. Beperkend om deze vraag 3 te beantwoorden is de kennis van de infectieve dosis van E. sakazakii (1000 cellen?). Voor een premature neonaat zou de infectieve dosis echter nog lager kunnen liggen, bvb. 100 cellen. Om voldoende veiligheid met deze onzekerheid betreffende infectieve dosis in te bouwen wordt geadviseerd om het houden van bereide zuigelingenvoeding in een bain-marie op $37^{\circ} \mathrm{C}$ te beperken tot 30 minuten.

\section{Vraag 4 : Hoelang mag toediening van zuigelingenvoeding in beslag nemen en bij welke} temperatuur?

Deze vraag wordt impliciet reeds beantwoord in vraag 3 . Bij het toedienen van de zuigelingenvoeding zal de temperatuur van de zuigelingenvoeding schommelen tussen $37^{\circ} \mathrm{C}$ en kamertemperatuur $\left(23^{\circ} \mathrm{C}\right)$ met generatietijden die respectievelijk zullen schommelen tussen 30-40 minuten. Opnieuw wordt geadviseerd om voldoende veiligheid te garanderen en de tijd van toediening te beperken tot 30 minuten waarbij maximum 1 vermenigvuldiging zal optreden.

In acht name van Vraag 3 en 4 samen zouden er dan in het slechtste geval 3 vermenigvuldigingen plaatsvinden (bv. van 1-2 cellen tot 8 à 16 cellen, een toename van ca. 1 log-eenheid) tijdens bereiden, warm houden en toedienen van bereide zuigelingenvoeding, een totaalproces dat maximum $1 \mathrm{~h}$ in beslag neemt.

Op voorwaarde dat er maar $1 \mathrm{~h}$ verloopt vanaf de opwarming van het gerehydrateerd melkpoeder tot $37^{\circ} \mathrm{C}$ tot het einde van de maaltijd is er een redelijke marge tussen aantal uitgegroeide E. sakazakii cellen (8 tot 16 cellen) en de infectieve dosis (100 tot 1000 cellen?). 
Vraag 5: Is het toegestaan om tijdens dezelfde maaltijd de bereide zuigelingenvoeding nogmaals op te warmen?

De terminologie "nogmaals opwarmen" zorgt voor verwarring en is niet wenselijk daar men in praktijk niet steeds de toegestane totale maximale periode bij $37^{\circ} \mathrm{C}$ van $1 \mathrm{~h}$ (zoals afgeleid uit combinatie van vraag 3 en 4) bij een dergelijke praktijk van opwarming, eerste toediening, heropwarmen en tweede toediening kan controleren. Wat eventueel kan bedoeld worden met vraag 5 is "mag de bereide zuigelingenvoeding warm gehouden worden?". Dit verwijst echter opnieuw naar de antwoorden op vraag 3 en 4 waar gesteld wordt dat vanaf de opwarming van het gerehydrateerd melkpoeder tot $37^{\circ} \mathrm{C}$ tot het einde van de maaltijd maximaal $1 \mathrm{~h}$ mag verstreken zijn.

\section{Randvoorwaarden bij de hantering van de richtlijnen}

\section{Productienorm van Enterobacter sakazakii in melkpoeder}

Door het opvolgen van de richtlijnen voorgesteld in dit advies zal men het risico op neonatale E. sakazakii-infecties virtueel uitschakelen. Dit geldt evenwel enkel op voorwaarde dat men een productienorm van afwezigheid van $E$. sakazakii per $10 \mathrm{~g}$ melkpoeder, die niet wettelijk verplicht is, respecteert.

\section{Internationale Context: FAO/WHO standpunt}

In het kader van dit advies is het interessant te verwijzen naar de besluiten van de FAO/WHO workshop "Enterobacter sakazakii and other microorganisms in Powdered Infant Formula", Genève, February 2004 (21).

Naast andere aspecten, stelt deze werkgroep_o.a. dat 
- het gebruik van commercieel steriele vloeibare kant en klaar formuleringen van zuigelingenvoeding of formuleringen die een effectieve hittebehandeling hebben ondergaan (bvb. door rehydratatie met voldoende warm water of door voldoende verhitting van het gerehydrateerd melkpoeder) is aanbevolen voor zuigelingen met verhoogd risico voor infectie met $E$. sakazakii (prematuren, zuigelingen waarvan de moeder met AIDS besmet is);

- de voedingsindustrie moet aangemoedigd worden om :

- $1^{\circ}$ een grotere range van commercieel beschikbare kant- en klare melken te produceren en

$2^{\circ}$ effectieve environmental monitoring in de productiesites uit te voeren;

- in de "code of practice" van de Codex Alimentarius meer rekening moet gehouden worden met de microbiologische risico's van melkpoeder en dat eventueel overwogen moet worden adequate specificaties voor $E$. sakazakii toe te voegen.

\section{Enterale voedingslijnen}

In het huidige advies (9) wordt omwille van het ontbreken van expertise binnen het Wetenschappelijk Comité van het FAVV met de enterale voedingswijze en de normale toedieningstijd van dit proces werd de problematiek van de enterale voedingslijnen niet geanalyseerd. Deze komen wel aan bod in de 2 buitenlandse rapporten met de volgende richtlijnen:

- In een Nederlands rapport (22): Beperk de verblijfstijd in gevulde reservoirs (en de enterale voedingslijnen) tot een minimum met dien verstande dat een periode van 8 uren niet wordt overschreden.

- In een Canadees rapport (23) en in een aanbeveling van de FDA (http://vm.cfsan.fda.gov/ dms/inf-Itr3.html) wordt aangeraden de tijd dat de voeding op kamertemperatuur wordt gehouden in een zak en in de bijhorende leidingen tijdens 
enterale voeding te beperken met een maximum van 4 uur. $\mathrm{Er}$ wordt duidelijk gewaarschuwd om langere tijden te vermijden.

\section{Besluit}

Het productieproces van melkpoeder laat niet toe dat melkpoeder een steriel product is en een mogelijks lage besmetting (productienorm: < 1 kve per $10 \mathrm{~g}$ ) met $E$. sakazakii kan aanwezig zijn. Bereiding dient te gebeuren door gekwalificeerd personeel met de nodige aandacht voor goede hygiënische maatregelen. $\mathrm{Er}$ wordt aanbevolen de bereide zuigelingenvoeding binnen maximaal $2 \mathrm{~h}$ te koelen tot $5^{\circ} \mathrm{C}$ en een maximum bewaartijd van $24 \mathrm{~h}$ te respecteren om vermenigvuldiging van eventuele $E$. sakazakii cellen te vermijden. Opwarmen van het gerehydrateerd melkpoeder tot $37^{\circ} \mathrm{C}$, warm houden en toedienen van bereide zuigelingenvoeding is een totaalproces dat maximum $1 \mathrm{~h}$ in beslag mag nemen. In het slechtste geval zouden in één uur bij $37^{\circ} \mathrm{C}$ drie vermenigvuldigingen plaatsvinden (vb. van 1-2 cellen tot 8 à 16 cellen, een toename van ca. 1 log-eenheid). Onder deze voorwaarde van maximum $1 \mathrm{~h}$ verblijftijd vanaf de opwarming van het gerehydrateerd melkpoeder tot $37^{\circ} \mathrm{C}$ tot het einde van de maaltijd is er een redelijke marge tussen aantal uitgegroeide E. sakazakii cellen (8 tot 16 cellen) en de infectieve dosis (100 tot 1000 cellen?). Het gebruik van commercieel steriele vloeibare kant en klaar formuleringen van zuigelingenvoeding is aanbevolen voor zuigelingen met verhoogd risico voor infectie met $E$. sakazakii (vb. prematuren). Door opvolgen van deze richtlijnen kan het risico op neonatale $E$. sakazakii-infecties sterk gereduceerd worden.

\section{Dankbetuiging}

De auteurs wensen alle leden van het Wetenschappelijk Comité van het FAVV te danken voor hun bijdrage en de opmerkingen bij het tot stand van deze aanbevelingen. 


\section{Literatuurlijst}

1.Codex Alimentarius Commission. Risk profile of Enterobacter sakazakii and other microorganisms in powdered infant formula. Codex Committee on Food Hygiene $36^{\text {th }}$ Session, Washington DC USA 29 March-3 April 2004

2. Peter, C.S., Feuerhahn, M., Bohnhorst, B., Schlaud, M., Ziesing, S., von der Hardt, H., Poets, C.F., 1999. Necrotizing enterocolitis: is there a relationship to specific pathogens? European Journal of Pediatry. 158, 67-70.

3. Agostini,C., Axelsson, I., Goulet, O., Koletzko, B., Michaelsen, K.F., Puntis, J.W.L., Rigo, J., Shamir, R., Szajewska, H., Turck, D., Vandenplas, Y., Weaver, L.T. 2004. Preparation and handling of powdered infant formula : a commentary by the ESPGHAN Committee on Nutrition. Journal of Pediatric Gastroenterology and Nutrition. 39, 320-322.

4. Lehner, A., Stephan, R. 2004. Microbiological, epidemiological, and food safety aspects of Enterobacter sakazakii. Journal of Food Protection. 67(12), 2850-2857.

5. Perez, M. 2004. Une bactérie tue deux nourrissons. Le Figaro, lundi 13 décembre.

6. Administratief Proces-Verbaal de dato 2 mei 2002 opgemaakt door Algemene Eetwareninspectie te Brussel.

7.Van Acker, J., De Smet, F., Muyldermans, G., Bougatef, A., Naessens, A., Lauwers, S. 2001. Outbreak of necrotizing enterocolitis associated with Enterobacter sakazakii in powdered infant formula. Journal of Clinical Microbiology. 39, 293-297.

8. Advies van de Hoge Gezondheidsraad met betrekking tot neonatale infecties veroorzaakt door Enterobacter Sakazakii HGR 7718 op website http://www.health.fgov.be/CSH_HGR/Nederlands/inhoud.htm). 
9. Wetenschappelijk Comité van het Federaal Agentschap voor de Veiligheid van de Voedselketen (FAVV) advies 28-2004 betreffende Risico's verbonden aan Enterobacter sakazakii (www.favv.be)

10. Iversen, C., Forsythe, S. 2003. Risk profile of Enterobacter sakazakii, an emergent pathogen associated with infant milk formula. Trends in Food Science and Technology. 14, 443-454.

11. Kandhai, C., Reij, M., Gorris, L., Guillaume-Gentil, O., Van Schothorst, M. 2004. Occurrence of Enterobacter sakazakii in food production environments and households. The Lancet, 363, 39-40.

12. Breeuwer, P., Lardeau, P., Peterz, M., Joosten, H. 2003. Dessiccation and heat tolerance of Enterobacter sakazakii. J. Appl. Microbiol. 95, 967-973.

13. Muytjens H.L., Roelofs-Willemse H., Jaspar, G.H.J. 1988. Quality of powdered substitutes for breast milk with regard to members of the family Enterobacteriaceae. Journal of Clinical Microbiology. 26: 743-746.

14. Nazarowec-White, M., Farber, J. 1997. Incidence, survival, and growth of Enterobacter sakazakii in infant formula. J. Food Prot. 60, 226-230

15. Iversen, C., Lane, M., Forsythe, S.J. 2004. The growth profile, thermotolerance and biofilm formation of Enterobacter sakazakii grown in infant formula milk. Letters in Applied Microbiology 38, 378-382.

16. Nazarowec-White, M., Farber, J. 1997. Thermal resistance of Enterobacter sakazakii in reconstituted dried-infant formula. Lett. Appl. Microbiol. 24, 9-13 
17. Edelson-Mammel, S.G., Buchanan, R.L. 2004. Thermal inactivation of Enterobacter sakazakii in rehydrated infant formula. J. Food Prot. 67 (1), 60-63.

18. Pagotto, F., Nazarowec-White, M., Bidawid, S., Farber, J. 2003. Enterobacter sakazakii: infectivity and enterotoxin production in vitro and in vivo. J. Food Prot. 66, 370-375

19. Havelaar, A.H., Zwietering, M. 2004. On the risk of Enterobacter sakazakii in infant milk formula. Letter to the Editor. Trends in Food Science and Technology 15,99-100.

20. Koletzko, B. (Ernahrungskommission der Deutschen Gesellschaft fur Kinderheilkunde und Jugendmedizin). 2004. Hinweise zur Zubereitung und handhabung von Säuglingsnahrungen. Monatschrift Kinderheilkunde 152 318-320.

21. Codex Alimentarius Commission. Joint FAO/WHO meeting on Enterobacter sakazakii and other microorganisms in powdered infant formula. Codex Committee on Food Hygiene $36^{\text {th }}$ Session, Washington DC USA 29 March-3 April 2004. Besluiten van de FAO/WHO workshop "Enterobacter sakazakii and other microorganisms in Powdered Infant Formula", Genève, February 2004 (http://www.who.int/foodsafety/publications/micro/feb2004/en).

22. Heuvelink A., Zwartkruis-Nahuis, J.T.M., van der A, H., Wit, B., van Oosterom, R., de Boer, E. 2003. Rapport 'Handhavingsactie Enterobacter sakazakii in zuigelingenvoeding' Project OT OT 0210. Keuringsdienst van Waren Oost.

23. Weir, E. 2002. Powdered infant formula and fatal infection with Enterobacter sakazakii. Canadian Medical Association Journal. 166,1570 